\title{
Construction of Training Platform for Electrical Control of Mechanical Equipments Based on MCGS
}

\author{
Mingxin Yuan ${ }^{1,2}$, Shanyue Xia ${ }^{2}$, Yue $\mathrm{Ge}^{2}$, Zhipeng Zhou ${ }^{2}$, Qi Wang ${ }^{1,2}$ \\ ${ }^{I}$ (Suzhou Institute of Technology, Jiangsu University of Science and Technology, Zhangjiagang, China) \\ ${ }_{2}^{2}$ (School of Mechatronics and Automotive Engineering, Jiangsu University of Science and Technology, \\ Zhangjiagang, China)
}

\begin{abstract}
Under the limited resources of hardware equipments, in order to improve the practical teaching quality of the electrical control of mechanical equipments and strengthen the application ability of programmable logic controller (PLC) control technology of students, the construction of the virtual training platform based on MCGS configuration software is proposed. Through the configuration software, the controlled system is designed firstly, and then the simulation system is controlled by PLC through the RS232 communication. According to the control requirements, control tasks and I/O distribution of the simulation system, the students can program their own ladder diagram to finish the system control. The practical teaching results show that the replacement from the traditional light-emitting diodes to the motion animation of the controlled system improves the students' interest, enriches the experiment contents and meets the requirements of practice teaching.
\end{abstract}

Keywords: Electrical control, MCGS configuration software, programmable logic controller, teaching reform, virtual training platform

\section{INTRODUCTION}

The electrical control of mechanical equipments is an application-oriented specialized course, which combining the traditional relay control and the modern PLC technology, and is one of the compulsory courses of mechanical engineering students. This course is characterized by obvious engineering application background and strong practice. In order to improve the teaching effect, during the theoretical teaching, the teachers should link up the teaching contents with the engineering background of electrical control to help the students to understand and grasp the course knowledge. Moreover, during the practical teaching, the teachers should strengthen the construction and guidance to help the students to apply the course knowledge to complete the electrical control system design in the practice, which helps students to improve the system design ability. However, the improvement of practical ability needs a large number of inputs regarding the experimental equipments. Now, there are more than 300 mechanical engineering students each year in Zhangjiagang campus of Jiangsu University of Science and Technology (JUST). In view of the practical requirements, the laboratory needs at least 10 sets of complete training device of programmable logic controller. Each device is not only expensive but also requires high maintenance costs, which is very difficult to the high education school which has little education funding, especially the Zhangjiagang campus of JUST. In addition, although the existing training equipments of PLC can provide good practice for the students, the control process is not very intuitive because the controlled objects are often replaced by the light-emitting diodes. Through the practical experiments, the students can not connect the practical results with the engineering practice, and their enthusiasm can not be stimulated to participate the practice.

Considering that the course regarding the electrical control of mechanical equipment is the specialized course of the students, and the application ability of course knowledge is directly related to their future employment competitiveness, the reform of the course is imperative. So, our teaching team provided the construction of the virtual training platform based on the MCGS configuration software. We developed a series of training items. The controlled systems are simulated through the MCGS configuration software, and they are controlled by the PLC. The students can finish the training through the programming of the PLC ladder diagram according to the control tasks and I/O distribution of the controlled systems, which not only increases the active participation of the students, but also helps the students to further enhance their applying ability of the PLC technology.

\section{LITERATURE REVIEW}

In view of the importance and characteristics of the course regarding the electrical control of mechanic equipments, some teaching reforms are carried out by the Chinese front-line teachers. Zhijiang Xuan (2011) introduced the engineering objects into the classroom teaching and combined the classroom knowledge with the actual project through the heuristic teaching. Shimin Wang (2009) designed a demonstration project regarding 
three floors based on the MCGS configuration software and introduced it into the classroom teaching to help students to understand the PLC-based control process. The theoretical teaching results show that the demonstration project stimulated students' interest in learning and deepen the understanding of classroom knowledge. Heyang Chen et al. (2011) provided a project-teaching method in the course regarding the electrical control of machine tools and PLC. During the classroom teaching, the student-oriented and teaching-learningdoing teaching modes were adopted, which helps to develop students' application ability of PLC technologies and enhance students' awareness of engineering. In order to overcome the drawbacks of traditional PLC experiments which were conducted in experiment box, Haiyu Zhen et al. (2008) provided the idea that the PLC experiment projects were developed by MCGS configuration software. The actual application results showed that not only the students' learning interests were enhanced, but also the practical teaching contents were enriched. In order to further improve the application ability of PLC control technologies of students, and improve the teaching effect of electrical control of mechanical equipments, Mingxin Yuan et al. (2013) performed the teaching reform for theoretical and practical teaching under guidance of engineering. On one hand the course knowledge was combined with the engineering technologies, and the classroom teaching was promoted by using the engineering project background, on the other hand the design and practice ability were strengthened by the experiments and curriculum design based on project tasks. The practical teaching shows that the project - based teaching aroused the learning enthusiasm of students, deepened the understanding and mastering of knowledge, and improved the application ability of PLC technologies.

\section{DESCRIPTION OF THE MCGS CONFIGURATION SOFTWARE}

MCGS (Monitor and Control Generated System) is a 32-bit version of configuration software for the industry automatic control developed by the Beijing Kunluntongtai Auto Software Technology Co., Ltd (H.P. Li, 2013). The software combines many functions, such as animation, process control, data acquisition, device control and output, network data transmission, engineering reports and so on, in one. It is a configuration software system for the quick construction and generation of the PC monitoring system, and can be run on Microsoft Windows 95/98/Me/NT/2000 operation systems. Now, the MCGS has been widely used in the fields of petroleum, electricity, chemicals, iron and steel mining, metallurgy, machinery, textile, aerospace, construction, materials, refrigeration transport, communications, food manufacturing and processing industry, water treatment, environmental protection, intelligent buildings, laboratories, and so on. Fig. 1 is the startup interface of MCGS 6.8 configuration software (embedded version).

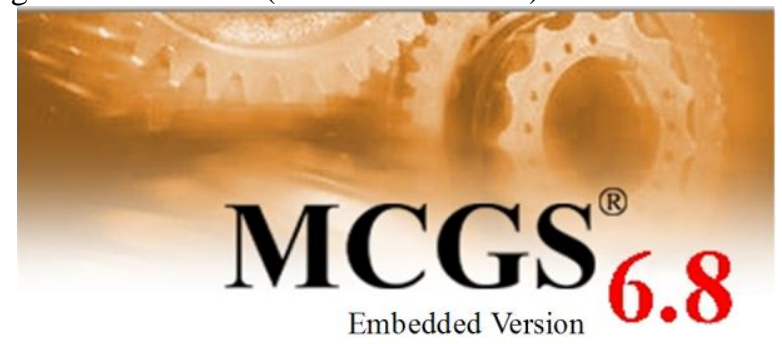

Beijing Kunluntongtai Auto Software Technology Co.,Ltd $\begin{array}{r}\text { Copyright (C) } 2009 \\ \text { All Rights Reserved }\end{array}$

Fig.1. Startup interface of MCGS 6.8 configuration software (embedded version)

MCGS configuration consists of "MCGS configuration environment" and "MCGS operating environment". The configuration process of all users is finished in the MCGS configuration environment. The MCGS configuration environment is a complete set of configuration tools, and help users to design and construct their own applications. The generated result of configuration is a database file. We call it the database of configuration result.

The MCGS operating environment is an independent operation system. It finishes the design targets and functions of users' configuration according to the user-specified way in the database of configuration result. The operating environment itself does not make any sense and can construct the user system together with the database of configuration result. Once the configuration works, the operation environment and database can run independently on a monitoring computer without configuration environment.

\section{Construction Of Virtual Training Platform}

\subsection{System structure}

The construction of virtual training platform for Electrical Control of Mechanical Equipments based on MCGS mainly uses the configuration technology to finish the simulation design of the controlled system. That is 
to say, the hardware work is replaced by the software, and the control process and control results are observed through the computer display, which makes the system control be more intuitive.

The structure of the whole training platform is shown in Fig. 2.

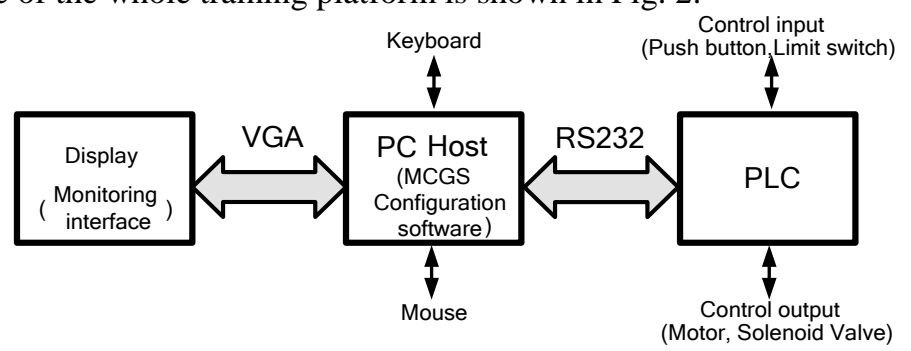

Fig.2. Structure of whole training platform

\subsection{Development of teaching cases}

In order to better carry out the training of electrical control based on the MCGS configuration software and improve the practice ability of the students, especially the application of the PLC ladder diagram, our teaching team has developed a series of teaching cases based on the MCGS6.8 configuration software (Embedded version) and Mitsubishi PLC (FX2N-48MR), such as four floors system, traffic lights system at crossroads, manipulator system, assembly line system, tower water system, automatic unloading truck system. Due to the limited space, in this section, only the development of automatic unloading truck system is introduced.

\subsubsection{Control requirements of automatic unloading truck system}

The designed simulation system of automatic unloading truck in this paper consists of truck, manipulator, goods, push rod, and so on. The manipulator is the key part of the automatic unloading truck system, and is responsible for the grab and release of the goods. It can move along the $\mathrm{X}$ axis and $\mathrm{Y}$ axis direction, that is to say, it can realize the horizontal and vertical movement. The control requirements of the automatic unloading truck system mainly include the basic grab, move and release of the goods by the manipulator.

When the start button is pressed, the automatic unloading truck system starts. If the automatic command is sent, the manipulator can move towards the goods and grab it to the target point according to a predetermined trajectory. Moreover, the automatic unloading truck system can also provide the manual button. The operator can operate the manipulator independently. In the control system, four movements (i.e. move left, move right, move down and move up) of the manipulator are provided separately.

\subsubsection{I/O distribution of PLC in automatic unloading truck system}

The I/O distribution of PLC is shown in Table 1.

Table 1 I/O distribution of PLC

\begin{tabular}{|l|l|l|l|}
\hline \multicolumn{2}{|c|}{ Input port } & \multicolumn{2}{c|}{ Output port } \\
\hline X00 & Manual mode & Y00 & Manipulator move right \\
\hline X01 & Single-step mode & Y01 & Manipulator move left \\
\hline X02 & Return to origin & Y02 & Manipulator move down \\
\hline X03 & Single-cycle mode & Y03 & Manipulator move up \\
\hline X04 & Continuous mode & Y04 & Manipulator clamp \\
\hline X05 & Move up & Y05 & Manipulator unclamp \\
\hline X06 & Move down & & \\
\hline X07 & Move right & & \\
\hline X10 & Start & & \\
\hline X11 & Close claw & & \\
\hline X12 & Open claw & & \\
\hline X13 & Reset & & \\
\hline X14 & Automatically start & & \\
\hline X15 & Move left & & \\
\hline X20 & Left limit switch & & \\
\hline X21 & Right limit switch & & \\
\hline X22 & Upper limit switch & & \\
\hline X23 & Lower limit switch & & \\
\hline & & & \\
\hline
\end{tabular}




\subsubsection{Programming of the PLC ladder diagram}

The PLC ladder diagram for automatic unloading truck system is finished based on the Gx Developer FX programming software. The GX Developer-FX is designed as a programming tool for the Mitsubishi programmable controller FX series. In the automatic unloading truck system, the PLC model is the FX2N78MR. The partial ladder diagram for the continuous operation mode of automatic unloading truck system is shown in Fig.3.

\subsubsection{Design of MCGS software for automatic unloading truck system}

The designed project by MCGS configuration software includes the main window, device window, user window and real-time database window. Each part is designed independently to finish different works and has different characteristics.

The design of the control screen is one of the major steps in the production of the entire project. It takes the actual controlled object as a template and simulates the operation of the controlled system. In MCGS configuration software, the data objects are used to describe the actual data of the controlled system, and the object variable is used to replace the traditional numerical variables. Through the analysis of the working requirements of the automatic unloading truck system, we build the real-time database as shown in Table 2 to simulate the automatic unloading truck system.

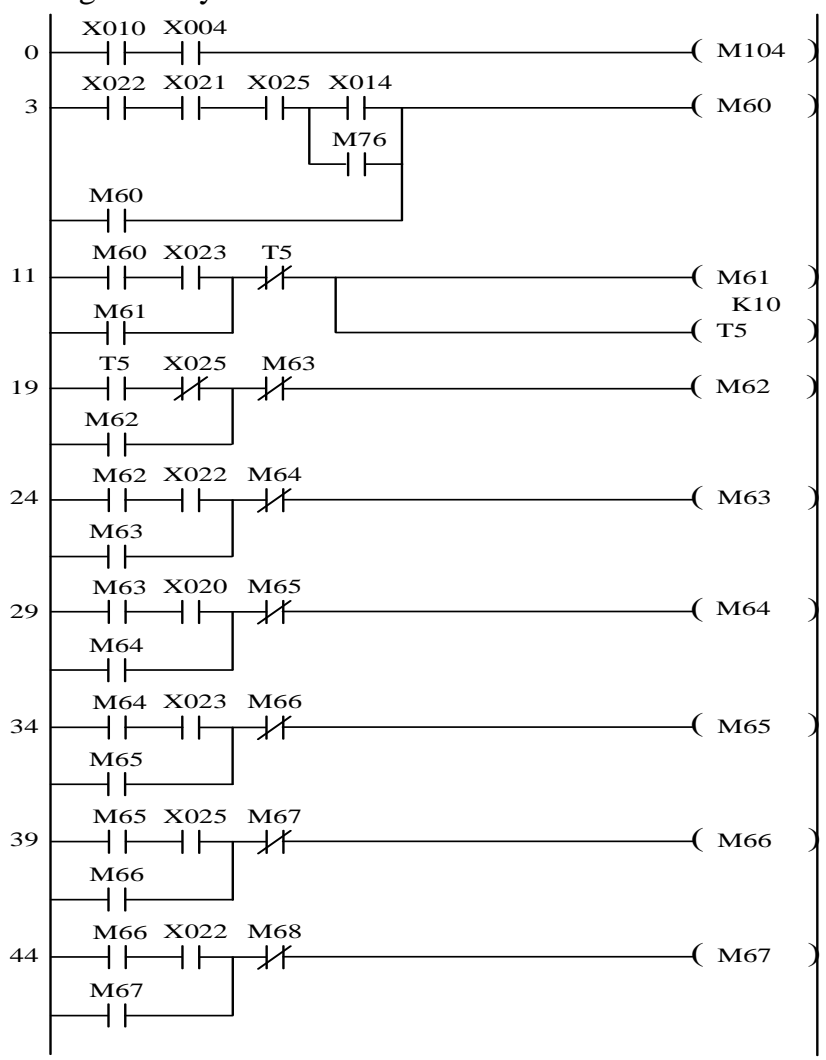

Fig.3. Partial ladder diagram for continuous operation mode

Table 2 Partial real-time database of automatic unloading truck system

\begin{tabular}{|c|c|c|c|}
\hline Name & Type & Name & Type \\
\hline Goods move left & On-off type & Control mode & On-off type \\
\hline Goods move up & On-off type & Start & On-off type \\
\hline Increment of goods moving up & Numerical type & Clock & On-off type \\
\hline Goods move down & On-off type & Increment of push rod moving & Numerical type \\
\hline Increment of goods moving down & Numerical type & Push rod moves right & On-off type \\
\hline Close claw & On-off type & Push rod moves left & On-off type \\
\hline Cross rod moves right & On-off type & Manipulator moves up & On-off type \\
\hline Cross rod moves left & On-off type & Manipulator moves down & On-off type \\
\hline Open claw & On-off type & Increment of manipulator moving & Numerical type \\
\hline$\vdots$ & $\vdots$ & $\vdots$ & $\vdots$ \\
\hline
\end{tabular}




\subsubsection{Communication between the MCGS software and PLC}

There are many connecting modes between the MCGS software and PLC. In this designed training system, the expensive RS232 serial communication is used (Gao et al. 2011). The setting of the serial port is realized in the device window of the MCGS configuration software. The device window is an important part of the MCGS system, and it is responsible for the connection between the MCGS and the external hardware devices. Through the device window, MCGS can read data from the external devices and control the state of the external devices, which realizes the real-time monitoring of the industrial process. The parameters of the RS232 serial port are set as follows: $9600 \mathrm{bps}$ with 8 data bits, no parity, and 1 stop bit (9600-8-N-1). The synchronous data acquisition method is used and the sampling period of MCGS is $200 \mathrm{~ms}$.

\subsection{Test of the developed engineering case}

Finally, the developed virtual training platform of automatic unloading truck system is tested. The experimental environment is shown in Fig.4.

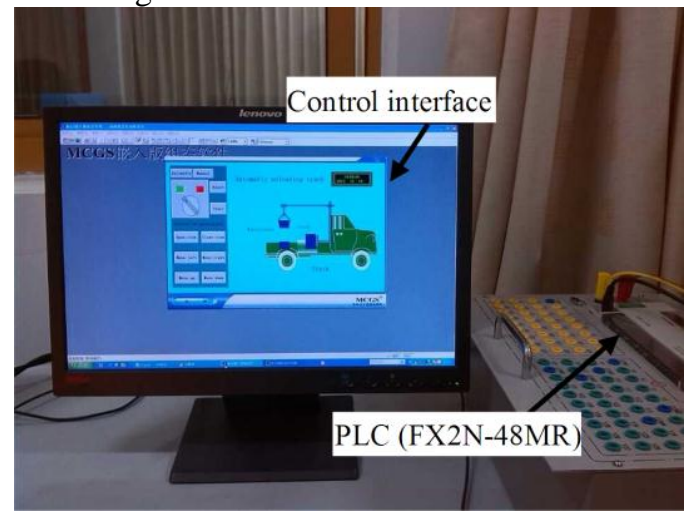

Fig.4. Experimental environment

Fig. 5 gives the partial test results. Fig.5(a) is the initial interface. There are some goods on the truck and the manipulator is located at the top of the socle beam. If we press the "Automatic" and "Start" buttons, the simulation system will automatically unload the goods on the truck according to the ladder diagram. Fig.5(b) shows that the manipulator has moved around the goods and grabbed a goods. Fig.5(c) shows that the manipulator has lifted the goods. Fig.5(d) shows that the manipulator was moving the goods to the back of the truck. The goods was eventually placed on the ground (see Fig.5(e)). Fig.5(f) shows that the manipulator has returned to the origin.

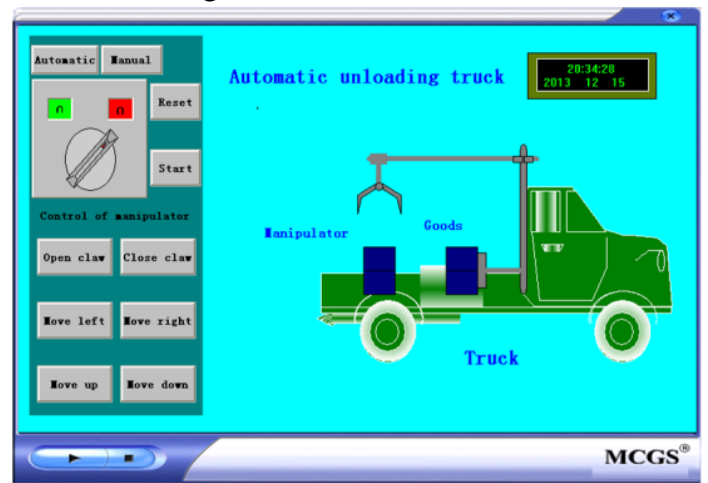

(a) Initial interface

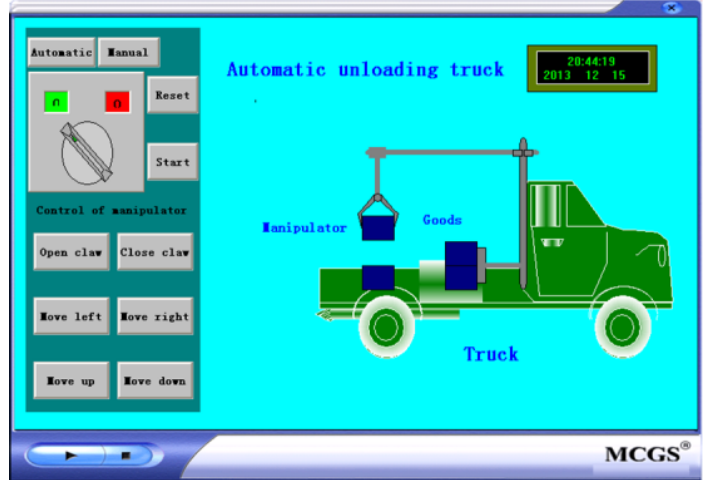

(c) Lift the goods

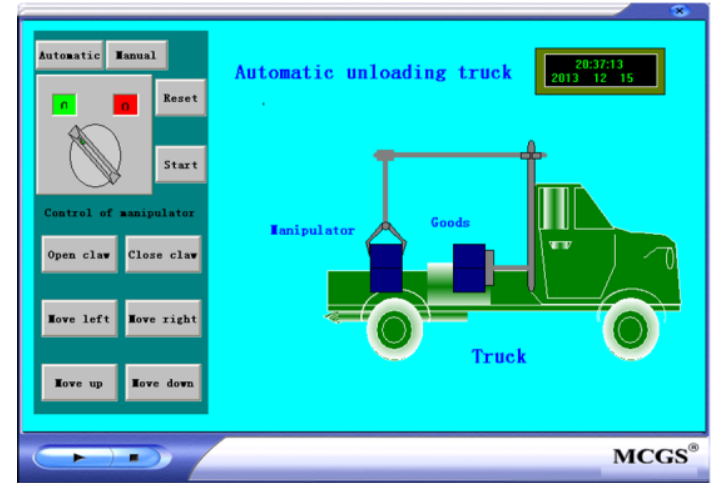

(b) Grab a goods

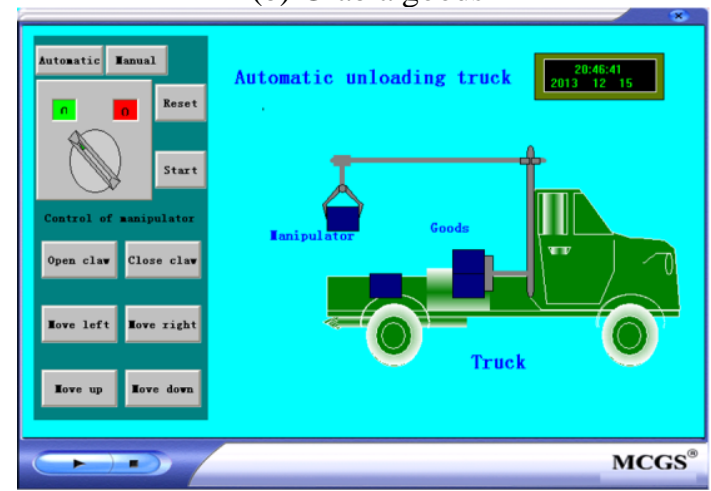

(d) Move the goods to the back of the truck 


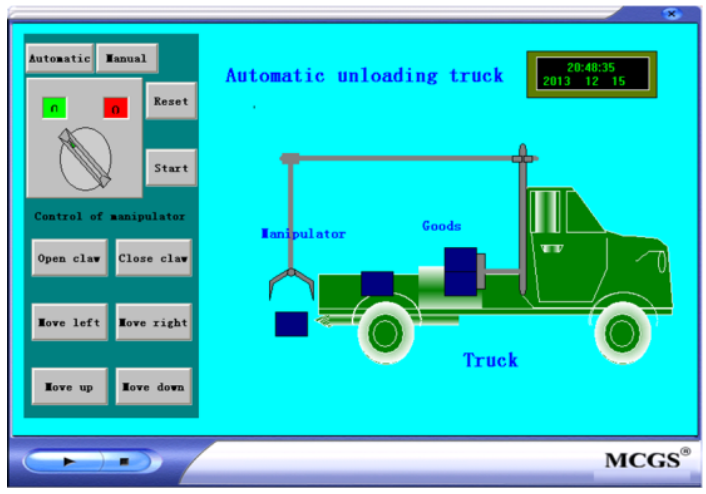

(e) Place the goods on the ground

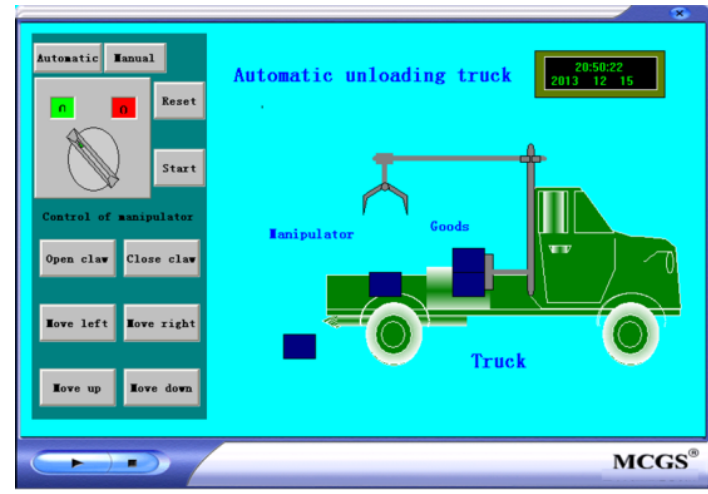

(f) Return to the origin

Fig.5. Partial test results

\section{Practice ArRangements Based On Virtual Training Systems}

After the virtual training systems for the electrical control are designed, the corresponding course practice for students can be carried out. Before the practice, the I/O distributions of PLC and the control requirements of different simulation systems are provided to the students. The students can finish different practices according to the following steps.

(1) Determine the control tasks according to the control requirements of the virtual training platform;

(2) Program the PLC ladder diagram based on the GX Developer;

(3) Download the ladder diagram to PLC;

(4) Under the communication between the configuration software and PLC, observe the working process of the controlled object through the simulation interface;

(5) Determine the correctness of PLC ladder diagram and complete the necessary modifications and debug;

(6) Finish the training report.

\section{CONCLUSION}

In order to further enhance the practice ability of electrical control of mechanical equipments and improve the practice teaching effect, in view of the shortage of education funding, our teaching team designed the virtual training system based on the MCGS configuration software. Through the MCGS configuration technologies, some controlled objects are designed, and the communication between the configuration software and PLC based on RS232 is realized. The students can finish the PLC ladder diagram according to the control requirements and I/O distribution, and determine its correctness based on the real-time dynamic simulation. Through the training platform, the students can not only efficiently grasp the course knowledge, but also improve the designing ability of the electrical system.

\section{Acknowledgements}

This work is supported by the Modern Educational Technology Project of Jiangsu Province (No. 2013R-24771), 2013 Teaching Reform and Teaching Study Project from Jiangsu University of Science and Technology (JUST), Key Teaching Reform and Teaching Study Project from Zhangjiagang campus areas of JUST, Key Course Construction of Suzhou Institute of Technology and Chinese-Foreign Cooperation in Running School Program of Suzhou Institute of Technology.

\section{REFERENCES}

[1] Z.J. Xuan, An exploration regarding project teaching method in PLC teaching, The Science Education Article Cultures, (2), 2011, 5960 .

[2] S.M. Wang, Skillfully develop PLC teaching tools-Operation of three floors based MCGS, Information technology \& Informatization, (6), 2009, 86-89.

[3] H.Y. Chen, M.L. Wang, S.Q. Liu, Application of project-teaching method in the course electrical control of machine tools and PLC, China Modern Education Equipment, (13),2010,12-14.

[4] Y.H. Zhen, S.X. Hua. Application of MCGS in PLC Experiment, Experiment Science \& Technology, 6(5), 2008,66-67.

[5] M.X. Yuan, Y. Shen, Q. Wang. Project-based teaching reform for electrical control of mechanical equipments under guidance of engineering, China Modern Education Equipment, (11),2013,42-44.

[6] H.P. Li, Control configuration technology and application: MCGS ( Xi'an, China: Xi'an Electronic Sience \&Technology University Press, 2013).

[7] A.B. Gao, M. Tian, N. Yu, Engineering design of mitsubishi PLC (Beijing, China: China Machine Press, 2011). 